\title{
'Meishuo': An Early-maturing Apricot Cultivar with Large Fruit from ZFRI-CAAS
}

\author{
Zhenyu Huang, Lehan Xia, and Yibin Feng \\ Zhengzhou Fruit Research Institute, Chinese Academy of Agricultural \\ Sciences, Zhengzhou 450009, Henan, China (ZFRI-CAAS)
}

\author{
Jingtao Hui \\ Comprehensive Testing Ground, Xinjiang Academy of Agricultural Sciences, \\ Urumqi 830012, Xinjiang, China
}

Shurui Qiao and Yuling Chen ${ }^{1}$

Zhengzhou Fruit Research Institute, Chinese Academy of Agricultural Sciences, Zhengzhou 450009, Henan, China (ZFRI-CAAS)

Additional index words. Prunus armeniaca, breeding, fruit quality, yield

Native to China, apricots (Prunus armeniaca $\mathrm{L}$.) have a long cultivation history, rich germplasm resources, and various resource types (Zhao et al., 2005). Apricots have an attractive appearance, unique flavor, pronounced nutritional value, and relatively early maturity, making them important to the early summer fruit markets (Chen et al., 2015; Wang et al., 2003). Local apricot cultivars in China usually have good flavor, but the fruit is small in size, which causes poor, unstable yield, while introduced apricot cultivars like 'Gold Sun' and 'Katy' are highly productive, but lack the sweetness and aroma of Chinese traditional cultivars, which cannot meet the needs of the market (Zhao et al., 2016).

'Meishuo' is a newly selected, earlymaturing apricot cultivar suitable for fresh consumption. The fruit matures in late May in Zhengzhou and the fruit development period is about $63 \mathrm{~d}$. The chilling requirement is about $637 \mathrm{~h}$ in Zhengzhou. The fruits are near globose in shape and have a pleasant golden-yellow peel color with a rosy red blush on the sunny side. The flavor is sweet-sour with a strong aroma, and the soluble solid content and total acid content are $15.1 \pm 0.6 \%$ and $1.59 \pm 0.21 \%$, respectively. The average fruit weight of 'Meishuo' apricot is $117.6 \pm 9.6 \mathrm{~g}$ and the maximum fruit weight is $184.3 \mathrm{~g}$, making it highly productive.

Received for publication 13 Aug. 2018. Accepted for publication 24 Sept. 2018.

This work was supported by the Agricultural Science and Technology Innovation Program (ASTIP) (CAAS-ASTIP-2015-ZFRI) and the Central Public-Interest Scientific Institution Basal Research Fund (No. 1610192018202).

We thank LetPub (www.letpub.com) for its linguistic assistance during the preparation of this manuscript.

${ }^{1}$ Corresponding author. E-mail: chenyuling@caas. cn.

HortScience Vol. 53(12) December 2018 transplanting in 2006. Under conventional management and pest control, seedlings started bearing in 2009 and investigations were conducted for both fruit and tree characteristics. Among these seedlings, hybrid number 1-10 was selected as an advanced accession for its better performance. From 2010 to 2011, further observations on hybrid 1-10 were carried out through grafting tests and the fruit quality traits and economic traits of different replicates were found to be uniform. We applied fruit thinning on fruits with abnormal phenotypes such as extremely small, malformed, cracked, disease infected, and pest injured. Meanwhile, some clones were propagated for subsequent pilot and regional tests in Henan and its neighboring provinces. In five successive years from 2012 to 2016, agronomic traits were tested and found to be stable across different clones and regions. Finally in 2017, accession 1-10 was approved by the Approval Committee for Improved Varieties of Forest Tree of Henan Province, and named 'Meishuo'.

\section{Description}

'Meishuo' was selected from hybrids of the cross between the sweet 'Mixiang' apricot cultivar (female parent) and the largefruit 'Katy' apricot cultivar (male parent). 'Mixiang' apricot is a volunteer seedling discovered in Xinmi City, Henan Province, China, and is characterized as sweet and fragrant. 'Katy' apricot was introduced into China from California, United States, in 1991 by Shandong Institute of Pomology. It features large fruit size, early maturation, and high productivity.

These parental apricots were hybridized in 2005 at the apricot germplasm repository of ZFRI-CAAS. Initially 137 hybrid seeds were harvested from the cross, with 68 seedlings surviving after germination and
Tree. The tree of 'Meishuo' has considerable vigor with a semicircle canopy and semiopening gesture. The trunk is thick and grey-brown in color. Perennial shoots are grey in color, and 1-year-old shoots are thick and strong, red brown in color, with smooth surfaces and no pubescence. The internode is about $1.9 \pm 0.2 \mathrm{~cm}$ long. The lenticels are great in number, medium in size, grey in color, and nearly round in shape. The vegetative growth of the tree lasts about $220 \mathrm{~d}$. The chilling requirement is about $637 \mathrm{~h}$ in Zhengzhou.

Leaf. The leaves are glossy, deep green in color, nearly round in shape, with heartshaped bases, short and acuminate apex,

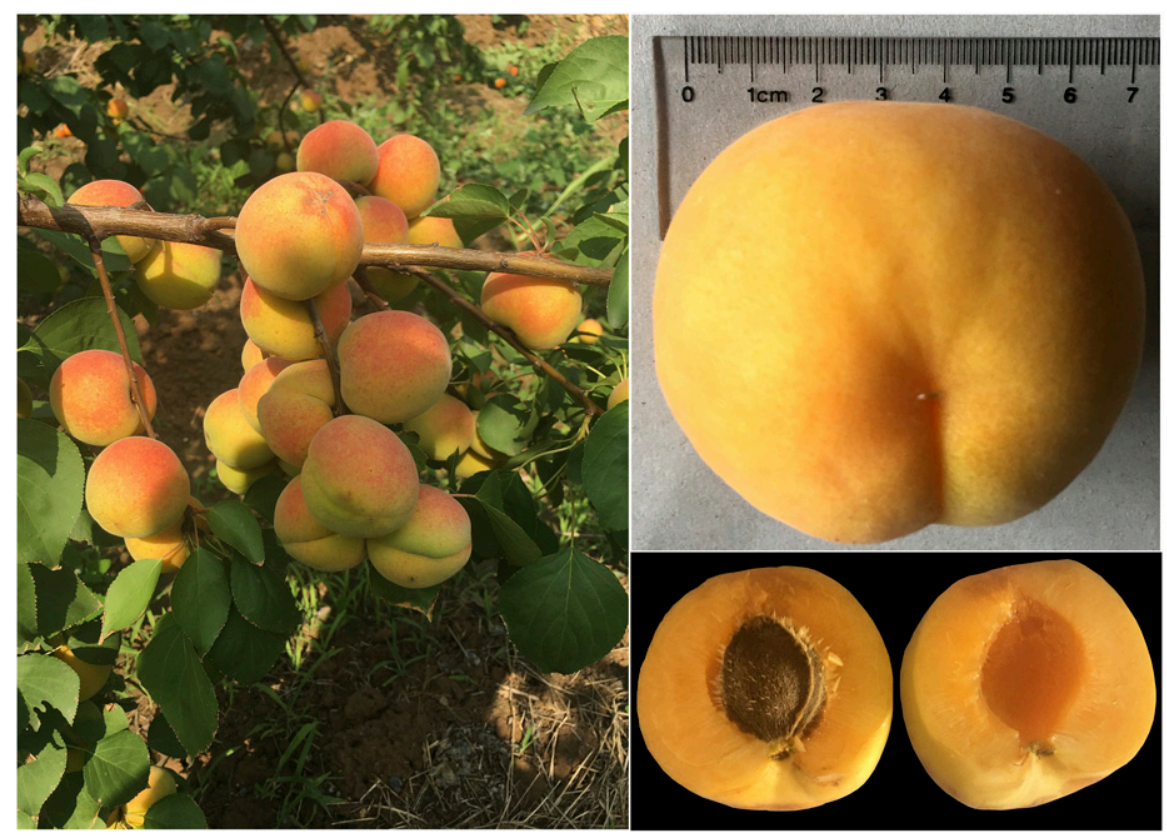

Fig. 1. Fruits of 'Meishuo' apricot. 


\begin{tabular}{|c|c|c|c|c|c|c|c|c|c|c|c|}
\hline Cultivar & $\begin{array}{c}\text { Sampling } \\
\text { years }\end{array}$ & $\begin{array}{l}\text { Ripening } \\
\text { date }\end{array}$ & $\begin{array}{l}\text { Avg fruit } \\
\text { wt (g) }\end{array}$ & $\begin{array}{l}\text { Fruit } \\
\text { shape }\end{array}$ & $\begin{array}{l}\text { Soluble } \\
\text { solid } \\
\text { content } \\
\left({ }^{\circ} \text { Brix }\right)\end{array}$ & $\begin{array}{l}\text { Total soluble } \\
\text { sugar } \\
\text { content }(\%)\end{array}$ & $\begin{array}{l}\text { Reducing } \\
\text { sugar } \\
\text { content }(\%)\end{array}$ & $\begin{array}{c}\text { Titratable acid } \\
\text { content }(\%)\end{array}$ & $\begin{array}{c}\text { Vitamin } \mathrm{C} \\
\text { content } \\
(\mathrm{mg} / 100 \mathrm{~g})\end{array}$ & $\begin{array}{c}\text { Pectin } \\
\text { content }(\%)\end{array}$ & $\begin{array}{c}\text { Chilling } \\
\text { requirement }(\mathrm{h})\end{array}$ \\
\hline Meishuo & $2012-16$ & 24-31 May & $117.6 \pm 9.6$ & Near globose & $15.1 \pm 0.6$ & $7.35 \pm 0.19$ & $2.84 \pm 0.07$ & $1.59 \pm 0.21$ & $11.5 \pm 1.3$ & $1.46 \pm 0.15$ & 637 \\
\hline Katy & $2012-16$ & 3-12 June & $95.5 \pm 6.3$ & Oblong globose & $12.7 \pm 0.4$ & $6.82 \pm 0.15$ & $2.71 \pm 0.11$ & $1.04 \pm 0.09$ & $7.73 \pm 1.0$ & $1.26 \pm 0.14$ & 706 \\
\hline
\end{tabular}

Data were obtained from three replicates and each replicates comprised three uniform fruits, and was expressed in mean \pm standard deviation.

and crenate margins. They are $8.3 \pm 0.3 \mathrm{~cm}$ in length, $6.2 \pm 0.3 \mathrm{~cm}$ in width, and $0.03 \pm 0.01$ $\mathrm{cm}$ in thickness. The main vein is yellow, while the lateral veins are yellow-green in color. The petioles are dark red in color and $1.8 \pm 0.2 \mathrm{~cm}$ in length. There are $3-4$ nectaries, medium in size and round in shape. In Zhengzhou, Henan Province, China, the leaf buds begin to push in late March and leaves start expanding in early April. The leaves start falling in early November and defoliation ends in mid-November.

Flower. The flowers comprise five pinkwhite petals, one pistil, and 32-41 stamens. Floral bud formation ability is strong for the 'Meishuo' apricot. The self-pollination rate of 'Meishuo' is very low and it is suggested to be a self-incompatible cultivar. The floral buds break out in early March, start flowering in late March, full bloom at the end of March, and flowering lasts 5-7 d.

Fruit. The fruit development period of 'Meishuo' apricot is about $63 \mathrm{~d}$, and the maturity date is around the end of May. The fruit shape is near globose and is beautiful in appearance (Fig. 1). The fruit of 'Meishuo' is extremely large in size: the average fruit weight is $117.6 \pm 9.6 \mathrm{~g}$, and the maximum fruit weight is $184.3 \mathrm{~g}$ (Table 1). The fruit ground color is golden yellow and is rosy red on the sunny side, and the percentage of fruit blush is about $35 \%$ to $60 \%$. The peel is of medium thickness and covered with pubescence. The peel can be easily separated from pulp. The flesh is yellow in color, thick and delicate in texture, with low fiber content, and the edible rate can reach up to $95.3 \%$. 'Meishuo' apricot is an attractive fruit with abundant juice, pleasant sweetness and sourness, and an intense fruity aroma. The content of soluble solids is about $15.1 \pm 0.6 \%$, the total soluble sugar content is $7.35 \pm 0.19 \%$, the reducing sugar content is $2.84 \pm 0.07 \%$, the total acid content is $1.59 \pm 0.21 \%$, the pectin content is $1.46 \pm$ $0.15 \%$, and the vitamin $\mathrm{C}$ content is $11.5 \pm$ $1.3 \mathrm{mg} / 100 \mathrm{~g}$. The 'Meishuo' apricot is a freestone variety, and the stone is oblong in shape. The average dry stone weight is $\approx 3.3 \pm 0.5 \mathrm{~g}$. The vertical diameter, transverse diameter and lateral diameter of the stone are $3.4 \pm 0.4 \mathrm{~cm}, 2.6 \pm 0.3 \mathrm{~cm}$, and $1.1 \pm 0.1 \mathrm{~cm}$, respectively. The kernel is bitter in flavor, flat in shape, and the average dry kernel weight is about $0.4 \pm 0.2 \mathrm{~g}$. The fruits can be stored at room temperature for about 5-7 d.

Growth and fruiting habits. In Zhengzhou, 10-year-old trees are about $3.6 \mathrm{~m}$ in height, with a $3.3 \mathrm{~m}$ canopy diameter and a $65.8 \mathrm{~cm}$ trunk circumference. The average length and diameter of annual shoots are 53.6 $\mathrm{cm}$ and $0.76 \mathrm{~cm}$, respectively. The fruits are mainly borne on bouquet spurs and short fruiting branches. For grafted seedlings of 'Meishuo' apricot, flowering starts at the second year and high yield period comes at the fourth year after grafting. The yield of 5-yearold tree is more than $40 \mathrm{~kg}$ per tree. The average yield is estimated to be $33,000 \mathrm{~kg}$ per hectare at full fruit period. Suitable pollinizers like 'Zaojinyan' and 'Gold Sun' apricots are needed with a ratio $1: 4$ to 6 between pollinizers and the 'Meishuo' apricot.

In conclusion, the 'Meishuo' apricot is an early-maturing cultivar with large fruit. It exhibits strong suitability to adverse circumstances. It is highly and stably productive, yielding high-quality fruits, which would take a strong place in the early summer fruit market. It can be cultivated in the Yellow and Huaihe River basins, and in the areas north of Qinling Mountain.

\section{Availability}

'Meishuo' is the property of Zhengzhou Fruit Research Institute, Chinese Academy of Agricultural Sciences (ZFRI-CAAS), and has been approved by the Approval Committee for Improved Varieties of Forest Tree of Henan Province (No. Henan S-SVAV-010-2017). Limited quantities of budwood are available upon request for all trial and research purposes and for commercial propagation.

\section{Literature Cited}

Chen, X.S., W.W. Guo, J. Xu, P.H. Cong, L.R. Wang, C.H. Liu, X.G. Li, S.J. Wu, Y.X. Yao, and X.L. Chen. 2015. Genetic improvement and promotion of fruit quality of main fruit trees. Scientia Agricultura Sinica. 48(17):3524 3540.

Wang, Y. Z., H.Y. Sun, and L. Yang. 2003. The latest progress of apricot in the world. Northern Fruits 2:1-2.

Zhao, F., W.S. Liu, N. Liu, X.H. Yu, M. Sun, Y.P. Zhang, and Y.Q. Zhou. 2005. Reviews of the apricot germplasm resources and genetic breeding in China. J. Fruit Sci. 22(6):687-690.

Zhao, X.P., X.L. Wu, X.C. Zhang, L.Y. Yuan, H.X Zhang, Q.Z. Cui, and L.Y. Li. 2016. Breeding of early maturity new apricot line 'Z08-7-34'. J. Hebei Agr. Sci. 20(2):77-78, 104. 